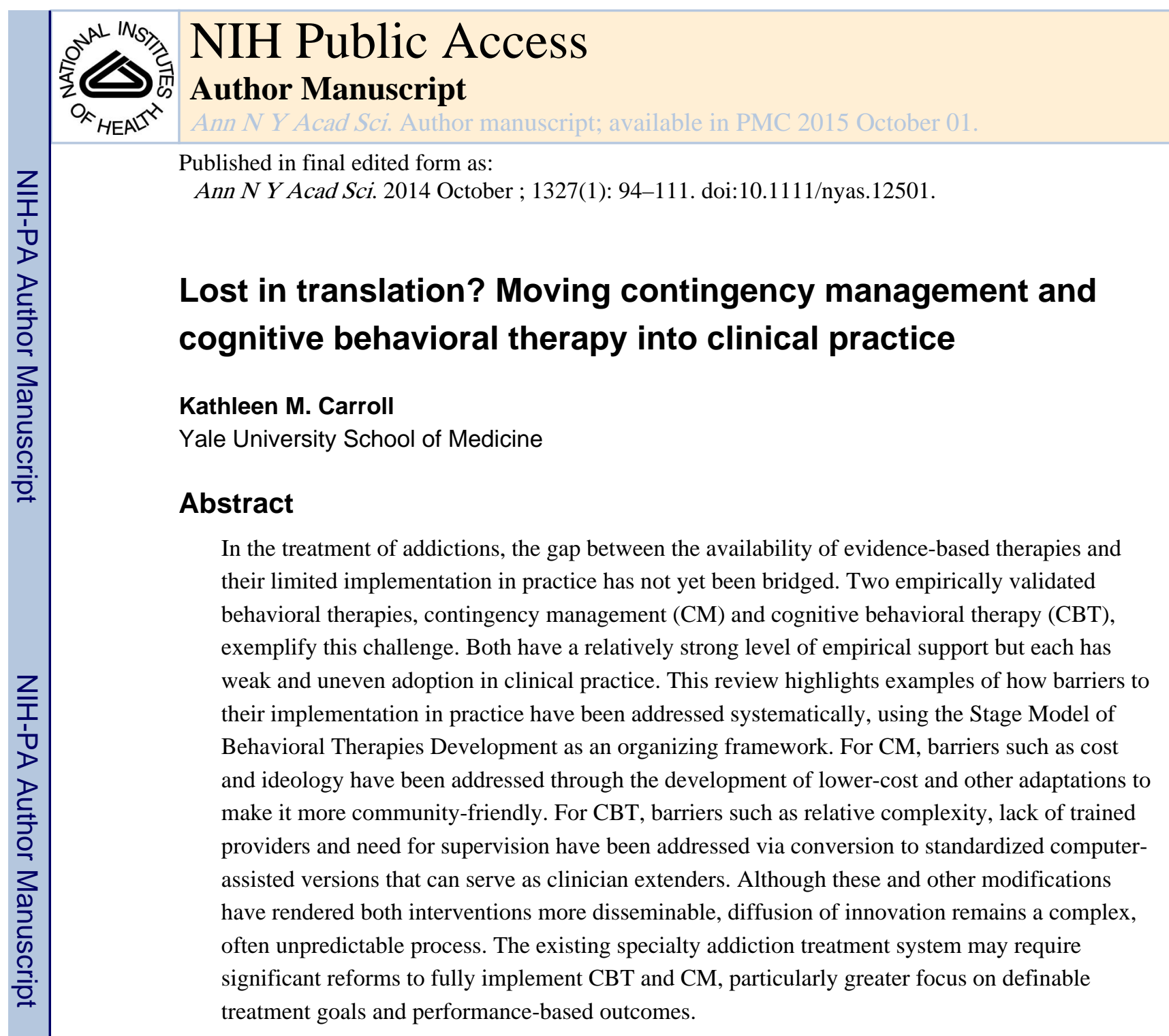

\title{
Keywords
}

Contingency management; cognitive behavioral therapy; dissemination; Stage model

\begin{abstract}
Over the past 30 years, enormous resources and scientific effort have been devoted to the development of effective treatments for addiction. This public health problem affects over 25 million Americans and their families with estimated annual costs of more than $\$ 180$ billion ${ }^{1}$ for medical care, lost productivity, and criminal justice system burdens. It is therefore of note that significant developments have been made in the development of effective behavioral and pharmacologic treatments for a range of addictions ${ }^{2}$. Important gains have been made in the pharmacologic treatments of opioid and alcohol dependence. For opioid dependence, methadone maintenance treatment and more recent adoption of buprenorphine and depot formulations of naltrexone, have had significant effects on extending the reach of treatment for heroin and prescription opioid use, significant problems in the US and globally ${ }^{3,4}$. In the treatment of alcohol use disorders, newer medications such
\end{abstract}

Corresponding author: Kathleen M. Carroll, PhD, Division of Substance Abuse, Yale University School of Medicine, 950 Campbell Avenue, 151D, West Haven, CT 06516, Kathleen.carroll@yale.edu. 
as naltrexone and acamprosate have been approved and are becoming more widely available. ${ }^{5-7}$ However, for some of the most commonly used abused substances, such as marijuana and cocaine, there are as yet no broadly effective or approved medications.

Important gains have also been made with respect to the development of effective behavioral therapies. Multiple behavioral therapies have been demonstrated to be effective ${ }^{2,8}$ and to improve outcomes when combined with medication. ${ }^{9}$ Effective therapies include brief motivational approaches, ${ }^{10-15}$ structured family approaches, ${ }^{16,17}$ and two that will be the subject of this review: contingency management and cognitive behavioral therapy. ${ }^{18}$

To date, however, most these evidence-based approaches have not yet become broadly implemented or adopted in clinical practice, ${ }^{2,19}$ for multiple reasons. Of the minority of individuals with drug or alcohol use disorders who receive treatment, ${ }^{20,21}$ only a small proportion receive treatment provided in accordance with practice guidelines and current scientific knowledge. ${ }^{22,23}$ The addiction treatment system operates independently from the general health care system, with the bulk of services delivered by independent practitioners or within specialty addiction treatment settings. ${ }^{24,25}$ This specialty addiction treatment system, primarily supported through public financing (Medicaid, block grants to states) has been underfinanced for decades, ${ }^{26}$ leading to a number of systemic problems and limitations: ${ }^{19}$ caseloads in community based clinics tend to be high. Waiting lists for residential or intensive programs tend to be long. Few clinics have the resources to address diverse patient needs, notably comorbid psychopathology or medical problems. Clinicians have limited ability to individualize treatments, as most clinical services provided in groups. Many programs lack medical personnel, ${ }^{27,} 28$ precluding availability of medications in many settings and perpetuating underutilization of available pharmacotherapies. ${ }^{6,23}$ The nonmedical clinical workforce tends to be poorly paid and has high rates of turnover. ${ }^{29}$ Training of this non-medical clinical counselor workforce infrequently includes adequate training in evidence-based treatments ${ }^{30,31}$ Attitudes of veteran counselors toward evidence based therapies remain mixed. ${ }^{32-34}$ These systemic problems result in an inauspicious environment for the adoption of novel approaches and assumption of their associated costs. Despite these barriers, some empirically validated approaches have had comparative success in penetrating the system in recent years.

Motivational interviewing (MI) ${ }^{35}$ has been embraced by the clinical community and adopted ${ }^{1}$ fairly widely, ${ }^{25}$ at least relative to other approaches. Diffusion of MI from research to clinical settings was guided by Roger's model of diffusion of innovation model, ${ }^{36}$ emphasizing factors associated with perceived advantage, compatibility with current practice, simplicity and ease of use, and trial ability; for example, approaches that allow a program to sample of the innovation before deciding to adopt it). MI is now implemented broadly across the US and internationally, fostered by a large network of trainers (Motivational Interviewing Network of Trainers), training resources (books, video examples, adherence measures), international conferences (see motivationalinterviewing.org), and results of research trials that have evaluated methods and

${ }^{1}$ Adoption as used here is consistent with Rogers definition, “.... decision to make full use of an innovation as the best course of action available" (p. 21). 
strategies for training clinicians to learn and use MI effectively in a range of settings (see Refs. 37-41). As interpreted through Roger's S-curve model of the process of adoption of an innovation, ${ }^{36} \mathrm{MI}$ adoption may be reaching a plateau, slowly leveling out after a steep climb of rapid acceptance by a large number of clinicians and providers after it was initially adopted by early innovators. ${ }^{42}$

In contrast, $\mathrm{CM}$ and $\mathrm{CBT}$ have made less progress in terms of diffusion to clinical practice. They remain in the early flat section of the $\mathrm{S}$ curve, adopted in some settings but unavailable in most. Both appear well-poised for dissemination. CM and CBT both display ample scientific evidence pointing to their efficacy, have been shown to be broadly effective across a range of addictions and related problems, are safe with few or no adverse events traced to their implementation, ${ }^{43}$ and are highly compatible with available pharmacotherapies (often demonstrating synergistic effects in combination). ${ }^{44,45}$

Relative to MI, adoption of CM and CBT in clinical practice in the addictions has progressed more slowly. Each of these approaches appears to require a number of adaptations to fit the existing specialty care and health systems. This review will focus on barriers to dissemination and other factors underlying this comparatively slow progress. I will trace the paths of development of these two interventions from their initial development and validation to current efforts to foster their translation to clinical practice, using the Stage Model of Behavioral Therapies Development ${ }^{46}$ as an organizing model. Remaining barriers to broader clinical adoption of CM and CBT will also be described. Health care reforms associated with the Affordable Care Act may provide a window for making these effective approaches more available to those who may benefit from them.

\section{Overview: the Stage Model}

The development and dissemination of both CM and CBT was fostered and accelerated by NIDA's Stage Model of Therapy Development (the Stage Model ${ }^{46}$ ). This model for development of behavioral interventions from basic behavioral research to interventions capable of being delivered in a range of clinical settings was innovative in the arena of behavioral therapies research because it articulated a series of stages that parallel the medications development process for novel pharmacotherapies. The Stage Model was also novel in defining an iterative process for addressing the multiple points where novel interventions were likely to fall off the implementation cliff, ${ }^{47}$ including acceptability by clinicians, payors, and patients.

Briefly, Stage I includes initial development and pilot/feasibility testing of new or untested treatments. Stage II consists principally of randomized controlled clinical trials of interventions that have shown promise or efficacy in initial studies. Stage III addresses issues of transportability of treatments whose efficacy has been demonstrated in at least two Stage II trials ${ }^{48}$. Recent refinement of the Stage Model $^{47}$ emphasizes that treatment development is not complete until an intervention reaches its highest level of efficacy and is can be implemented for the maximum number of people in the population for which it was developed. Thus, issues such as training of clinicians, provision of ongoing fidelity monitoring with supervision, and adaptation of the intervention to address the realities of 
clinical care while retaining its active ingredients figure prominently in the later stages of treatment development. Later stages emphasize maximizing external validity (effectiveness research in Stages III and IV) by testing interventions in community clinics with delivery by community providers. Implementation and dissemination research define the final Stage V. 49

This model has proven useful as a framework for intervention development because it makes explicit that different research questions are relevant to each stage of a treatment's development. The model then articulates appropriate research paradigms for each level of development. As described in the sections below, the development and dissemination of CM and CBT show how the Stage model can be used to organize programs of research on novel behavioral therapies by moving them from early translational research to broad implementation.

\section{Contingency management}

\section{Stage I research in contingency management}

Contingency management approaches have strong scientific bases in operant conditioning and in systematic analysis of behavior. ${ }^{50}$ These approaches have central tenets: (1) behaviors (including substance use) that are reinforced are likely to be repeated, and (2) drug and alcohol use can be sensitive to environmental consequences. ${ }^{50}$ As applied to illicit drug and alcohol use, contingency management approaches arrange systematic application of behavioral consequences in order to change target behaviors.

Contingency management procedures were first implemented in United States addiction treatment in the context of methadone maintenance programs. Two key features of methadone maintenance fostered initial research on the efficacy of contingency management in this setting. First, daily delivery of methadone allowed frequent monitoring of illicit drug use and abstinence via regular urine toxicology screens. Second, the availability of natural rewards in this environment (e.g., take home bottles and other desirable clinic privileges) made it possible to meaningfully reward positive behavior change at relatively low cost. Bigelow, Stitzer, and their colleagues ${ }^{51,52}$ pioneered the evaluation of methadone takehome privileges as a reward for decreased illicit drug use. In a series of well-controlled trials, these researchers demonstrated: (1) the relative benefits of positive (for example, rewarding desired behaviors such as abstinence) compared with negative (for example, punishing undesired behaviors such as continued drug use through discharges or dose reductions) contingencies, ${ }^{53}$ (2) the attractiveness of take-home privileges over other incentives available within methadone maintenance clinics; ${ }^{51}$ and (3) the relative effectiveness of rewarding drug-free urine specimens compared with other target behaviors. ${ }^{54}$

Another early set of studies evaluated contingency management with focus on enhancing adherence to naltrexone. This was important. Despite the many potential advantages of naltrexone opioid antagonist treatment, including its nonaddicting nature, benign side effect profile in abstinent individuals, low risk of diversion and potential cost savings, naltrexone treatment programs remained comparatively rare and underutilized as compared to 
methadone maintenance programs. ${ }^{55}$ This was largely due to problems with retention. During the induction phase, about $40 \%$ of patients drop out during the first month of treatment and $60 \%$ drop out by three months. ${ }^{56}$ In the 1970s, preliminary evaluations of behavioral interventions used to address naltrexone's weaknesses, including providing financial incentives for compliance with naltrexone, ${ }^{57,58}$ suggested the promise of these strategies. However, these interventions were not widely adopted. Compliance remained a major problem. Naltrexone treatment and research thus dropped off considerably until the recently, when long acting depot formulations became available. ${ }^{4}$

\section{Stage II}

Until the 1980 's, contingency management approaches remained largely limited to methadone maintenance and inpatient programs, as natural reinforcers were not as studied in outpatient treatment settings. There has been no effective pharmacotherapy for cocaine use disorder. The need for a potent behavioral approach to address epidemic-level cocaine dependence was addressed by Stephen Higgins and his colleagues at the University of Vermont. Drawing from the Community Reinforcement Approach of Azrin and colleagues, ${ }^{59}$ Higgins developed a novel system of behavioral incentives for cocaine abstinence that had four organizing features grounded in principles of behavioral pharmacology: (1) drug use and abstinence must be swiftly and accurately detected, (2) abstinence must be positively reinforced, (3) drug use must result in loss of reinforcement, and (4) emphasis is placed on the development of reinforcers to compete with drug use. ${ }^{60,61}$ In this approach, urine specimens are required three times weekly to systematically detect each episodes of drug use, based on the half-life of readily-detectable cocaine metabolites that are excreted in the urine. Abstinence, verified through drug-free urine screens, is reinforced through a voucher system in which patients receive points redeemable for items consistent with a drug-free lifestyle (e.g., movie tickets, music downloads, small personal items). Third, a key feature of this approach is that number of points earned increases with each consecutive cocaine-free urine specimen submitted, thus encouraging periods of sustained abstinence. Finally, cocaine use results in loss of reinforcement, in that submission of a cocaine-positive specimen, or failure to submit a specimen at the scheduled time, results in loss of reinforcement. When this occurs, earned points are reset to their starting values. ${ }^{60}$

In a series of well-controlled clinical trials, Higgins demonstrated high acceptance, retention, and rates of abstinence for patients receiving this approach, when compared with results of standard counseling oriented toward Twelve Step programs. ${ }^{61}$ Moreover, Higgins demonstrated that rates of abstinence do not decline substantially when less-valuable incentives are substituted for the voucher system. ${ }^{62}$ The value of the voucher system itself, in producing good outcomes, as opposed to other program elements, was demonstrated by comparing the behavioral system with and without vouchers. ${ }^{63}$ Although the strong withintreatment effects of $\mathrm{CM}$ decline somewhat after the contingencies are terminated, the voucher system has been shown to have durable effects ${ }^{64}$. Individuals who display longer sustained periods of abstinence within treatment tend to have better long term outcomes after treatment ends. 
Following Higgins' initial work, the efficacy of a wide variety of CM procedures was replicated in other settings and samples. Taken together, this body of research highlights the consistency and robustness of the effects of CM. For example, Silverman and colleagues have demonstrated impressive sustained effects of a reinforcement-based therapeutic workplace. Illicit drug users gain entry to paid employment contingent on submission of drug-free urines prior to entering the workplace ${ }^{65-67}$ Milby and colleagues demonstrated efficacy of providing housing for homeless substance users contingent on demonstrating abstinence on submitting drug-free urines. ${ }^{68-70}$ Silverman and Higgins demonstrated the efficacy of $\mathrm{CM}$ on reducing cocaine dependence within methadone maintenance programs. ${ }^{71,72}$ These approaches have also proven effective in adolescent populations. Krishnan-Sarin and colleagues have demonstrated the efficacy of CM procedures, delivered on-site in high schools, to reduce adolescent smoking. ${ }^{73,74}$ The work by Henggeler and colleagues in implementing CM alone or as a component of Multisystemic Therapy (MST) in state systems supports dramatic improvements in this challenging population. ${ }^{17,75-81}$

$\mathrm{CM}$ procedures have also been demonstrated to address other critical challenges in healthcare, including medication adherence. Even the most potent pharmacotherapy will be ineffective if the patient doesn't take it as prescribed ${ }^{82} \mathrm{CM}$ has been shown to enhance compliance with medications for HIV among drug users, ${ }^{83-85}$ and to enhance retention and adherence in naltrexone programs. ${ }^{86-88}$ The power of CM to enhance compliance is underscored by a recent meta-analysis of 21 studies in which $\mathrm{CM}$ had been used to enhance medication adherence in tuberculosis, stroke prevention, schizophrenia, substance use, and HIV treatments. There was a large overall effect (average effect size $=0.77$ ), ${ }^{89}$ with larger effects for longer durations of reinforcement, larger incentive magnitude, and more frequent (at least weekly) reinforcement. CM may also be used to address key problems in other areas of medicine. A recent pilot by our group demonstrated that $\mathrm{CM}$ could be used to reinforce abstinence from cigarettes in cancer patients waiting for thoracic or throat surgery. ${ }^{90}$ Abstinence in this setting is especially desirable as continued cigarette use is a risk factor for postsurgical complication and poor outcomes. Finally, recent work by Higgins further suggests the broader effects of CM interventions. ${ }^{91,92}$ Clinical trials of voucher based CM among pregnant women who smoke produced robust effects of $\mathrm{CM}$ on reduction of cigarettes use during and after pregnancy, and on birthweight of the infants..$^{93,94}$

\section{Stage III and beyond}

The studies reviewed above underscore the power of $\mathrm{CM}$ interventions in wide range of health behaviors. A growing number of meta-analyses show few other behavioral interventions that have such consistent and robust effects on behavior. ${ }^{18,}$ 95-97 Thus, the relative scarcity of CM interventions in clinical practice is especially notable. In systematic surveys of clinicians and program directors, the most frequently-cited obstacles to implementing CM in clinical practice include the relatively high cost of the rewards/ incentives, ideological issues (e.g., paying drug users to do the right thin), practical considerations that include the limited use of frequent urine screens to verify abstinence by many clinical programs, and limited knowledge of and training in CM. ${ }^{48,98-101}$ 
These and related issues characterize much of Stage III research, where investigators attempt to move novel treatments to the clinic and hit the implementation cliff full on. These obstacles typically revolve around issues of generalizability (Will this treatment work with different patients and in different settings?), implementation (What kind of training and what kinds of trainers are necessary for what kinds of clinicians to learn this new technique?), cost (Compared with the costs of implementing the new treatment, what are the savings, particularly in comparison to existing methods?), and acceptability (How acceptable is a new treatment to both clinicians, patients, and payers outside of research settings?). ${ }^{48,} 102$

Nancy Petry's work exemplifies an elegant and systematic approach to addressing these Stage III issues. To address issues of cost, Petry developed a lower-cost variable ratio reward system. She demonstrated that a variable ratio schedule of reinforcement that provides access to large reinforcers (with low probabilities) is effective in retaining patients in treatment and reducing substance use. Rather than earning vouchers, patients earn the chance to draw from a bowl and win prizes of varying magnitudes. The prizes are stored onsite for immediate delivery. Prizes range from small $\$ 1$ items (bus tokens, McDonald's coupons) to larger $\$ 20$ prizes (portable radios, watches, and phone cards), to jumbo $\$ 100$ prizes (for example, small televisions). As in the Higgins system, sustained periods of abstinence are encouraged: the number of chances to draw from the fishbowl increases with each consecutive drug-free urine sample submitted. This prize system is less expensive than the standard voucher system. Only a proportion of behaviors are reinforced with a prize, and the magnitude of most prizes is small. Efficacy of CM has been retained. In a study of 42 alcohol-dependent veterans who were randomly assigned to standard treatment or standard treatment plus $\mathrm{CM}, 84 \%$ of the CM subjects were retained in treatment throughout an eightweek period, compared with $22 \%$ of standard treatment subjects. By the end of the treatment period, $69 \%$ of those receiving CM had not experienced a relapse to alcohol use, but only $39 \%$ of those receiving standard treatment were abstinent. ${ }^{103}$ There were similar findings in a subsequent trial with cocaine abusers. ${ }^{104}$

These initial studies were followed by others that systematically addressed key questions regarding breadth, feasibility, and utility of CM procedures when implemented in community treatment programs. ${ }^{105-107}$ For example, Petry demonstrated the efficacy of this procedure in reinforcing retention in HIV drop-in centers, ${ }^{108}$ in reinforcing alternative goals ${ }^{109}$ and in a range of desired outcomes. ${ }^{10-114}$ Responding to concerns by community programs that urine specimens are collected much more frequently in CM programs than in standard clinical practice, Petry demonstrated that for patients in outpatient treatment who started treatment while abstinent (e.g., the initial urine submitted was negative for cocaine), reinforcing retention alone is as effective, and less expensive, than reinforcing abstinence. ${ }^{115,116}$ Since most outpatient treatment in the US is delivered in groups, Petry demonstrated that CM could be effectively integrated into group settings. ${ }^{117,}{ }^{118}$ Later studies demonstrated that significant levels of abstinence could be achieved among cocaine using samples with magnitudes of reinforcement as low as $\$ 200$ per participant, ${ }^{119}$ and that lower cost prize based systems were as effective, or more effective, than voucher based reinforcement at comparable reinforce magnitudes. ${ }^{120,121}$ Concerns from providers that drawing prizes from the fishbowl could increase gambling were addressed with evidence that these CM procedures did not increase gambling. ${ }^{43,122,123}$ In response to concerns that 
$\mathrm{CM}$ procedures were too complex for delivery by community providers, Petry conducted training studies indicating the efficacy of CM is retained when delivered by community providers. She and others noted that training in CM procedures improves clinicians' attitudes toward CM. ${ }^{12480}$ Henggeler and colleagues have conducted similar work on implementing $\mathrm{CM}$ within large state-wide systems for adolescent treatment,, demonstrating that with adequate support by clinical leadership and access to resources, community based clinicians can implement $\mathrm{CM}^{78,80}$

Issues of acceptability of $\mathrm{CM}$ in community settings were addressed in large part by the NIDA Clinical Trials Network (CTN), ${ }^{125-127}$ a national research-provider partnership that conducts effectiveness research via testing empirically validated therapies in community based settings. The efficacy of adding CM to standard treatments that targeted stimulant use (cocaine and methamphetamine) was evaluated in two CTN multisite trials conducted in 8 outpatient drug free settings and 6 methadone maintenance settings. ${ }^{126}$ Although implemented at a lower magnitude of reward than the studies that established the efficacy of this approach, the addition of CM to standard treatment provided significant benefits in retention and abstinence. ${ }^{128,129}$ This national study provided a platform for a range of programs and clinicians to gain experience with $\mathrm{CM}$ procedures. There were high levels of enthusiasm and demonstrable changes in attitudes regarding use and efficacy of CM among providers exposed to this approach. ${ }^{130}$ Training materials geared toward facilitating implementation of CM procedures as implemented in the CTN and other in clinical settings are available through a series of blending materials developed in partnership with SAMHSA, ${ }^{127}$ and can be downloaded at http://www.bettertxoutcomes.org/ bettertxoutcomes/.

CTN studies of CM also provided a platform to address the cost of incentive. In a series of studies on the cost-effectiveness of CM procedures in community programs, $\mathrm{CM}$ was associated with increased cost and effectiveness (\$148-258 per additional week of abstinence, with lower costs in methadone versus outpatient settings). ${ }^{131-133}$ Since the CTN trials, a number of the participating programs have adopted CM procedures using novel strategies to acquire prizes. ${ }^{134}$

Given the severe constraints of funding within the US addiction treatment, the cost of CM procedures, however effective, remains an obstacle to implementation in many settings. These costs are not reimbursed by many state, Medicare, or private insurers, a point to which we will return in the final section of this review. However, as health care reform leads to greater focus on improved quality and cost constraints, health care systems that are responsible for the overall health of their patients have begun adopting CM. CM is now recognized and has been adopted as a standard treatment in the United Kingdom National Health Service through NICE guidelines. ${ }^{135}$ The US Veterans Administration recently initiated implementation of CM procedures in 108 VA stations, providing intensive training and direct support for purchase of incentives, urine testing, and other costs of CM. ${ }^{136} \mathrm{VA}$ clinical staff trained in $\mathrm{CM}$ through this initiative has demonstrated high acceptance and readiness to implement CM. ${ }^{137}$ Given that the VA is the largest healthcare system in the country, the results of this trial will have important implications for wider adoption of CM in healthcare systems. 


\section{Cognitive behavioral interventions}

\section{Stage I and II}

The challenges of implementing CBT in clinical practice in the addictions differ from those faced by either CM or MI. CBT has had broader acceptability within the addiction field and throughout psychiatry for many years. It is generally held to be among the most effective behavioral approaches for a range of psychiatric disorders. ${ }^{138}$ A comprehensive CBT model for the addictions was first developed by Marlatt and colleagues, ${ }^{139,}, 140$ adapted in part from cognitive behavioral approaches developed for depression and anxiety disorders ${ }^{141}$ and based on principles of behavioral pharmacology and learning theory. Following initial validation in alcohol-users, ${ }^{142}$ CBT has been shown to be effective across a wide range of substance use disorders, including marijuana, cocaine, and nicotine dependence. ${ }^{18,143} \mathrm{CBT}$ is compatible with a number of other treatment approaches, including pharmacotherapy ${ }^{144,145}$ and traditional counseling approaches. ${ }^{146}$

As applied to addictions, two key defining features of CBT are (1) an emphasis on functional analysis of drug use, understanding its antecedents and consequences, and (2) emphasis on skills training. These typically include strategies for: (1) understanding the patterns that maintain drug use and developing strategies for changing these patterns; (2) understanding craving, craving cues, and the development of skills for coping with craving; (3) recognizing and challenging the cognitions that accompany and maintain patterns of substance use; (4) increasing awareness of the consequences of even small decisions (e.g., which route to take home from work), and the identifying seemingly irrelevant decisions which can culminate in high risk situations; (5) development of problem solving skills, and practicing application of those skills to substance-related and more general problems; and (6) developing skills for assertively refusing offers of drugs, as well as reducing exposure to drugs and drug-related cues. These skills are useful in their application to helping patients control and stop substance use. They also provide building blocks for effective behavior in multiple contexts. ${ }^{147}$ For example, skills used to cope with craving can easily be applied to other aspects of affect control, the principles used in the sessions on seemingly irrelevant decisions are use can easily be adapted to improve decision making skills, and substance use refusal skills can easily be transferred to more effective and assertive responding in a number of situations.

Although acceptability of CBT is relatively high, multiple lines of evidence suggest that effective implementation of CBT in many substance abuse treatment settings is comparatively rare. ${ }^{148} \mathrm{CBT}$ interventions are often implemented at much lower levels of fidelity and skill than those seen in efficacy trials. Our program of systematic research on CBT as guided by the Stage model illustrates how treatments can be adapted to better fit clinical practice through an iterative process. ${ }^{149}$ Stage 1 work focused on defining and manualizing $\mathrm{CBT}{ }^{150}$ for drug addiction, leading to its initial validation as treatment for illicit drug use. ${ }^{151-153}$ Project MATCH, ${ }^{154}$ a large multisite trial of behavioral therapies for alcohol use disorders, set standards for therapist training and implementation in addiction treatment trials that allowed CBT to move rapidly into Stage 2. 
Stage 2 efficacy research in CBT for the addictions focused on efficacy research. It chiefly involved comparisons of CBT with other therapies that included supportive counseling, contingency management, ${ }^{154-157}$ and pharmacotherapies that included desipramine ${ }^{156}$ and disulfiram. ${ }^{158,159}$ An important finding to emerge from this work was the delayed emergence of effects of CBT relative to other therapies (a sleeper effect). ${ }^{160,161}$ Subsequent work emphasized identification of processes and strategies that might underlie the durability that provides one of the most salient aspects of CBT. Learning, practice, mastery and generalization of strategies for fostering cognitive and behavioral control over substance use emerged as prime candidates. ${ }^{162}$

As the efficacy of CBT was established by a number of groups and settings, ${ }^{163-169}$ a general observation was that was that the overall level of adherence to CBT, as detected by independent evaluators rating session, ${ }^{170,171}$ was lower than expected. This occurred even when CBT was delivered by carefully trained, closely supervised therapists and despite clear discriminability of CBT and comparison treatments. ${ }^{171,172}$ The correspondence of therapists versus independent rater's assessments of adherence was quite low in multiple studies.

Therapists consistently report much higher levels of adherence and integrity than do independent raters of the same sessions. ${ }^{173,174175}$ Several studies evaluating treatment fidelity in the Clinical Trials Network found that clinicians routinely reported that CBT was an key component of the treatment they routinely provided ${ }^{176}$ and independent fidelity raters found that, interventions associated with were virtually undetectable. ${ }^{148,177}$ Thus, implementation and fidelity emerge as key issues for dissemination of CBT in clinical practice.

\section{Stage III}

Appreciation of the difficulty and cost of delivering reasonably large doses of CBT in clinical practice was further heightened by results of Stage III dissemination/efficacy research. Recognizing that many substance use clinicians in community settings received no formal training or certification in CBT or other empirically validated approaches, ${ }^{26,30,31}$ we evaluated the efficacy of different training strategies in bringing community based, predominantly masters-level counselors, to levels of fidelity and skill equivalent to those achieved in efficacy trials In this randomized training trial, ${ }^{178} 78$ community-based clinicians were randomized to three training conditions (CBT manual only, interactive website, or 3-day didactic seminar in CBT with supervision via feedback on session tapes). Before training, independent ratings of mock CBT session indicated this low baseline levels of adherence and competence in CBT. ${ }^{178}$ Combined didactic training and supervision, the classic clinical trials model provided the only training condition that brought the majority of clinicians to levels of adherence and competence appropriate for a randomized clinical trial. This training procedure was also the most expensive to provide. Similar findings regarding the relative efficacy of intensive didactic training followed by performance monitoring and feedback have been found by others, including Miller's work on training clinicians in motivational interviewing ${ }^{41}$ and Rawson's work in CBT counselor training in South Africa. ${ }^{179}$ 
Regardless of the effectiveness of these and similar methods of training community clinicians to implement CBT and other EBTs, ${ }^{40,41,180-182}$ high rates of turnover in clinical programs and the lack of available supervision on EBTs in clinical practice ${ }^{29,} 183$ suggest these approaches may not be feasible when taken to scale. Thus, many years of work resulted in identification of multiple barriers to implementing CBT in the addiction treatment system with adequate levels of fidelity and standardization. These include very high caseloads and administrative demands on clinical staff, their limited time for focus on individual patients; the tendency for most outpatient care to be delivered in group settings that dilutes the dose of treatments and the relative complexity of CBT relative to supportive approaches.

These issues led to our development of a computer-assisted version of CBT (CBT4CBT ${ }^{184-186}$ ). In developing a computer-assisted version of CBT that could be used with minimal clinician or staff assistance, it was necessary to clearly specify what the program was intended to convey. We conceived of CBT4CBT as a cognitive coping skills training machine. The programming uses multimedia features to demonstrate implementation of targeted coping skills in realistic settings. We emphasize coping skills generalization to address a range of behaviors and problems in addition to addiction. The CBT4CBT program, delivered as an adjunct to treatment as a clinician extender, ${ }^{184}$ provides a standardized means in which we can convey specific components of CBT with a high and consistent levels of fidelity. CBT4CBT was designed to be engaging, user-friendly and to require no previous experience with computers or reading skills (any material presented in text was also read aloud). The program collects no PHI. The program is media rich, using games, cartoons and exercises to illustrate points. At its core is a series of videos that, present connected scenes of engaging characters, portrayed by professional actors for each module. The characters first experience a common, difficult situation; then demonstrate use of targeted skills to successfully negotiate the situation without resorting to drug use.

Two randomized trials of CBT4CBT have been completed in community based settings. The first, conducted in an outpatient addiction treatment setting, evaluated outcomes among treatment seeking individuals with a range of substance use problems. ${ }^{185} \mathrm{We}$ compared outcomes for standard treatment alone (typically group and individual counseling) to those of standard treatment plus CBT4CBT). Participants were predominantly alcohol, cocaine, marijuana, and opioid dependent. Use of multiple substances was reported by most participants $(80 \%)$. At the end of the 8-week trial, participants assigned to the CBT4CBT condition submitted significantly fewer urine specimens that were positive (34\% vs. 53\%) for any type of drugs and displayed a trend toward longer continuous periods of abstinence during treatment. A six-month follow-up of $82 \%$ of the intention to treat sample indicated significantly better durability of effects of CBT4CBT over standard treatment, for both selfreport and urinalysis data. ${ }^{187}$ The sleeper effect of clinician-delivered CBT appeared to be with computer delivered therapy. The second randomized trial was conducted with a larger, more homogeneous but challenging population, that is, methadone maintained individuals with cocaine use disorders. As with the first study, acceptance of and satisfaction with the CBT4CBT program by the participants was high. Significantly more individuals maintained at least three weeks of continuous abstinence within treatment. As with the initial trial, the 
CBT4CBT program was associated with better outcomes through a 6 month follow-up than standard methadone maintenance treatment. ${ }^{188}$

A major potential advantage of computer delivered therapies is their relatively low cost compared to clinician-delivered therapies. As access to computers and the internet continues to grow, even in rural and remote locations, these therapies become more accessible. ${ }^{189,} 190$ Thus, using the same methods to evaluate cost and efficacy as were used in the evaluations of $\mathrm{CM}$ as described above, Olmstead reported that, as practiced in the trial, the incremental cost effectiveness ratio (ICER) for producing an additional drug free urine specimen cost \$21 for CBT4CBT compared with standard outpatient treatment. ${ }^{191}$ This amount compared favorably to ICERs for Petry's CM in methadone programs in the CTN studies (\$70), CM in outpatient programs in the CTN ( $\$ 146$, with those costs increases driven by additional urine toxicology screens and administrative costs associated with purchase and management of the prizes), and traditional clinician-delivered CBT (\$159) for the same outcome. Furthermore, when taken to scale (a single computer used by many patients), CBT4CBT quickly dominated treatment as usual. ${ }^{191}$ Evaluation of CBT4CBT, as well as numerous other computerized therapies for the addictions ${ }^{192-196}$ is still in its early stages. ${ }^{197-201}$ Nevertheless, this line of research promises to make a form of empirically validated therapy more broadly available to individuals who might benefit from it.

\section{Remaining challenges for dissemination of evidence-based therapies: cost, fidelity, and performance standards}

As described in the sections above, systematic research on CM and CBT, guided by the Stage Model, has resulted in development and validation of modified versions of these treatments that are more 'community friendly' than their original versions. Multiple obstacles to their dissemination have been addressed. Both CM and CBT have been modified for more efficient delivery at lower cost, while retaining efficacy in community settings. Both have been shown to be feasible to implement in a variety of specialty addiction treatment settings. Training studies have demonstrated that clinicians can be trained to implement these treatments effectively. Both have been shown to be compatible with effective pharmacotherapies. Both are well accepted by a range of patient samples. While some clinicians may have been wary of both of these approaches early in their development, exposure to these forms of treatment in practice had led to greater acceptability 13677,78 .

Nevertheless, we are cautious about predicting widespread adoption of $\mathrm{CM}$ interventions, CBT4CBT and other web-based interventions with the specialty addiction treatment in the near future. Diffusion of intervention is not a rapid process ${ }^{36,49}$, for many reasons. One of the more prominent issues is cost. Most new, empirically validated therapies carry with them increased costs and hence a strategy to pay for those costs. For medications, these costs include the medication itself as well as physician and staff time medical evaluation and ongoing monitoring. Once approved and included on formularies, some of those costs are reimbursed. For behavioral therapies in general, additional costs include those associated with clinician training, supervision, and ongoing fidelity monitoring. In the case of CM, additional costs include those of regular urinalyses, the rewards and prizes themselves, and 
administrative time required by staff to acquire, stock and manage the incentive system. ${ }^{132,133,202}$ For computerized therapies, these include the cost of computers and setup, staff training, and site licenses. ${ }^{191}$ Novel medications, which, once approved, can leverage the large infrastructure of the pharmaceutical industry to support dissemination. By contrast, there is no such dissemination infrastructure for novel effective behavioral therapies and no sustainable means of paying for them. There is as yet no third party reimbursement for covering the cost of CM or CBT4CBT (and other computerized versions of empirically validated therapies). This leaves no viable means for their large-scale adoption, because the potential cost-offsets of providing evidence based treatments are not realized within most specialty treatment settings. In contrast, Screening, Brief Intervention and Referral to Treatment (SBIRT), a key component of which is motivational interviewing ${ }^{203}$ has become reimbursable in many states, and thus likely to continue to play key roles in MI's recent growth and broad adoption.

At the same time, integration of MI into clinical practice has also been characterized by variable outcomes in ways that appear linked to high levels of variation in the fidelity and skill with which it is implemented. ${ }^{42}$ Indeed, another major barrier to implementation of virtually all empirically validated therapies is the lack of quality-control measures in most mental health and addiction treatment systems. Clinical supervision, based on systematic review of clinicians' implementation of an evidence-based treatment with objective ratings of fidelity and the provision of feedback, is the gold standard in efficacy trials that establish the effectiveness of behavioral trials. Such careful clinical supervision is rarely available in clinical practice $29,204,205$ and is not reimbursable in most areas. A notable exception is the VA, which has recently begun to provide supervision, monitoring and feedback as a strategy to foster availability of empirically validated therapies. ${ }^{206}$ Without supervision or some means for regular review of clinicians' work, it is unlikely that empirically validated therapies will be implemented with adequate fidelity or intensity.

Given the state of the current specialty addiction treatment system, it is unclear that these or other empirically validated therapies can be effectively implemented within it. ${ }^{1,26,207}$ Issues including quality of the workforce, availability of training and supervision, high levels of staff turnover, emphasis on providing more individuals with access to care without corresponding increases in capacity, disconnection from the broader health care and psychiatric treatment system undermine the quality of care in the current system. ${ }^{24,} 208$ Thus, a major issue, not unique to the addiction field, ${ }^{209}$ but highly salient for this review, is the lack of emphasis on performance and outcome in the current system. In most settings, the primary reimbursement models (fee for service and fixed budget) lack proper incentives for provision of quality or cost-effective care. ${ }^{2,24}$ Residential and inpatient treatments provide very few incentives for evidence-based treatments within these relatively expensive services. In outpatient settings, providers are reimbursed at the same rate for individual or group counseling, regardless of what actually occurs during counseling sessions. ${ }^{2}$ Where there is no accountability or demand to provide quality evidence-based treatment, there is no incentive to do so.

A number of recent initiatives have attempted to address these issues by mandating that providers provide evidence of 'quality indicators' such as shorter wait times to enter 
treatment or better retention in episodes of care. ${ }^{1,210}$ However, these indices of process and engagement, do not measure relevant outcomes. While these metrics are relatively easy to quantify concretely, don't necessarily closely relate to meaningful treatment outcomes. For example, in a recent analyses of outcome data from over 400participants in randomized clinical trials of behavioral and pharmacologic treatments for cocaine dependence, retention as measured by days in treatment was not significantly related to cocaine use or general functioning in the next year. ${ }^{211}$ Process indicators such as engagement and retention in treatment are meaningful only where treatment is of high quality and when engagement and retention correlate with outcome goals.

A closely related issue is lack of emphasis on clearly defined, clinically meaningful outcomes in addiction treatment. Perhaps the most challenging obstacle to adoption of evidence-based therapies like CM and CBT and even MI in clinical care in the addiction is the striking lack of information on actual patient outcomes in most clinical settings. It is impossible to obtain from the vast majority of clinical programs. Even a rough estimate of the rates of their enrollees who attain meaningful periods of abstinence or maintain good outcomes after they leave treatment is not available from most programs. Even those who report some outcome data usually focus only on the small subset of patients who remain in treatment. ${ }^{212}$ It is also worth noting the infrequency with which many clinical programs monitor their patient's primary symptom (recent drug or alcohol use) at each contact, although urine and breath analysis are reasonably inexpensive and a quite reliable means of monitoring symptoms. As noted earlier, one of the more disturbing obstacles to implementing CM in clinical settings is the lack of routine use of urine monitoring in clinical care. A key implication is that we can't begin to improve care until we measure it effectively and report it honestly-integration of this core feature of CM into clinical care might do much to improve the quality of treatment.

While it is difficult to reach consensus on outcome indicators that might be reported across clinics and programs, ${ }^{213}$ the lack of clear data on substance abuse treatment settings keeps the field disconnected from, and to some degree, distrusted by, other areas of medicine, which are moving more rapidly to adopt performance-based outcomes and performance standards. ${ }^{214}$ While addiction treatment is far from reaching consensus on a single indicator, a reasonable proxy might encompass (1) abstinence (or not using illicit drugs and alcohol at a harmful level), (2) working (or fulfilling school and family responsibilities), and (3) not being involved in illegal activities or the legal system. Adoption of this kind of practical, patient-oriented outcomes reporting would be novel in both the clinical and research arenas in the addictions system. We have recently reported analyses of data from 5 clinical trials of treatment seeking cocaine-dependent individuals, focusing on rates of good outcomes that included abstinence and lack of problems in legal, occupational, and psychiatric functioning in Addiction Severity Index reporting. We sought data from the end of treatment and the end of a one-year follow-up, based on aggregated data from. ${ }^{215}$ For the full sample $(\mathrm{N}=424)$, $11 \%$ met this criterion at the end of treatment, and $21 \%$ did so at the end of the one-year follow-up period. End of treatment rates of success using these criteria were markedly higher for individuals treated with $\mathrm{CM}$, while end of follow-up rates were best for $\mathrm{CM}$ and CBT. ${ }^{215}$ These rates may serve as potential benchmarks as the field moves toward emphasis on treatment performance and outcome. 
Encouraging emphases on practical outcomes like these by itself should spur adoption of evidence based treatments to improve patient outcomes and quality of care. As in the rest of the health care system, providers respond to incentives. ${ }^{216}$ While paying-for-performance has potential drawbacks, evidence is emerging that emphasis on outcomes improves care and with it, adoption of evidence based treatments and practices. ${ }^{217,} 218$ Major changes will be needed before specialty addiction treatment moves to a system of routinely tracking and reporting patient outcome. This difficult process, likely to encounter enormous resistance, will provide a starting point for realistically evaluating the value of our treatments and the quality of care we provide to our patients. Changes associated with Affordable Care Act and other components of health care reform, including parity of substance use and mental health treatment with other disorders, enhanced access to care as well as better integration of substance use treatment in primary care, are poised to accelerate this process and foster adoption of evidence based care.

\section{Acknowledgments}

Support was provided by National Institute on Drug Abuse grants R37-DA 015969 and P50-DA09241.

\section{Literature cited}

1. Hoffman, KA.; McCarty, D. Improving the quality of addiction treatment. In: Miller, PM., editor. Interventions for Addiction: Comprehensive Addictive Behaviors and Disorders. Vol. 3. Academic Press; San Diego, CA: 2013. p. 579-588.

2. Institute of Medicine. Improving the Quality of Health Care for Mental and Substance Use Conditions. The National Academies Press; Washington, DC: 2006.

3. Vocci FJ, Acri J, Elkashef A. Medication development for addictive disorders: the state of the science. The American journal of psychiatry. 2005; 162:1432-1440. [PubMed: 16055764]

4. Gastfriend DR. Intramuscular extended-release naltrexone: current evidence. Annals of the New York Academy of Sciences. 2011; 1216:144-166. [PubMed: 21272018]

5. O'Malley SS, Froehlich JC. Advances in the use of naltrexone: an integration of preclinical and clinical findings. Recent developments in alcoholism : an official publication of the American Medical Society on Alcoholism, the Research Society on Alcoholism, and the National Council on Alcoholism. 2003; 16:217-245.

6. Jonas DE, et al. Pharmacotherapy for adults with alcohol use disorders in outpatient settings: a systematic review and meta-analysis. JAMA : the journal of the American Medical Association. 2014; 311:1889-1900.

7. Anton RF, et al. Combined pharmacotherapies and behavioral interventions for alcohol dependence: the COMBINE study: a randomized controlled trial. JAMA : the journal of the American Medical Association. 2006; 295:2003-2017.

8. National Institute on Drug Abuse. Principles of Drug Addiction Treatment: A Research Based Guide. NIDA; Bethesda, MD: 2007.

9. Carroll KM, Onken LS. Behavioral therapies for drug abuse. The American journal of psychiatry. 2005; 162:1452-1460. [PubMed: 16055766]

10. Babor TF, et al. Screening, Brief Intervention, and Referral to Treatment (SBIRT): toward a public health approach to the management of substance abuse. Substance Abuse. 2007; 28:7-30. [PubMed: 18077300]

11. Miller WR. Rediscovering fire: Small interventions, large effects. Psychology of Addictive Behaviors. 2000; 14:6-18. [PubMed: 10822741]

12. Burke BL, Arkowitz H, Menchola M. The efficacy of motivational interviewing: a meta-analysis of controlled clinical trials. Journal of consulting and clinical psychology. 2003; 71:843-861. [PubMed: 14516234] 
13. Rubak S, et al. Motivational interviewing: a systematic review and meta-analysis. British Journal of General Practice. 2005; 55:305-312. [PubMed: 15826439]

14. Heckman CJ, Egleston BL, Hofmann MT. Efficacy of motivational interviewing for smoking cessation: a systematic review and meta-analysis. Tobacco control. 2010; 19:410-416. [PubMed: 20675688]

15. Jensen $C D$, et al. Effectiveness of motivational interviewing interventions for adolescent substance use behavior change: a meta-analytic review. Journal of consulting and clinical psychology. 2011; 79:433-440. [PubMed: 21728400]

16. Stanton MD, Shadish WR. Outcome, attrition, and family-couples treatment for drug abuse: A meta-analysis and review of the controlled, comparative studies. Psychological bulletin. 1997; 122:170-191. [PubMed: 9283299]

17. Henggeler SW, et al. Eliminating (almost) treatment dropout of substance abusing or dependent delinquents through home-based multisystemic therapy. American Journal of Psychiatry. 1996; 153:427-428. [PubMed: 8610836]

18. Dutra L, et al. A meta-analytic review of psychosocial interventions for substance use disorders. American Journal of Psychiatry. 2008; 165:179-187. [PubMed: 18198270]

19. Institute of Medicine. Bridging the Gap Between Practice and Research: Forging Partnerships with Community-Based Drug and Alcohol Treatment. National Academy Press; Washington, DC: 1998.

20. Regier DA, et al. The de facto US mental health and addictive disorders service system: Epidemiological Catchment Area prospective one-year prevalence rates of disorders and services. Archives of general psychiatry. 1993; 50:85-91. [PubMed: 8427558]

21. Norquist G, Regier DA. The epidemiology of psychiatric disorders and the de facto mental health care system. Annual Review of Medicine. 1996; 47:473-479.

22. McGlynn EA, et al. The quality of health care delivered to adults in the United States. The New England journal of medicine. 2003; 348:2635-2645. [PubMed: 12826639]

23. D'Aunno T, Pollack HA. Changes in methadone treatment practices: results from a national panel study, 1988-2000. JAMA : the journal of the American Medical Association. 2002; 288:850-856.

24. Stewart MT, Horgan CH. Health services and financing of treatment. Alcohol research \& health : the journal of the National Institute on Alcohol Abuse and Alcoholism. 2011; 33:389-394. [PubMed: 23580023]

25. Miller WR, et al. Disseminating evidence-based practices in substance abuse treatment: A review with suggestions. Journal of substance abuse treatment. 2006; 31:25-39. [PubMed: 16814008]

26. McLellan AT, Carise D, Kleber HD. Can the national addiction treatment infrastructure support the public's demand for quality care? Journal of substance abuse treatment. 2003; 25:117-121. [PubMed: 14680015]

27. Horgan, CM.; Levine, HJ. The substance abuse treatment system: What does it look like and whom does it serve?. In: Lamb, S.; Greenlick, MR.; McCarty, D., editors. Bridging the Gap between Practice and Research: Forging partnerships with community-based drug and alcohol treatment. National Academy Press; Washington, DC: 1999. p. 186-197.

28. McLellan, AT. What we need is a system: Creating a responsive and effective substance abuse treatment system. In: Miller, WR.; Carroll, KM., editors. Rethinking Substance Abuse: What the Science Shows and What We Should Do About It. Guilford; New York: 2006. p. 275-292.

29. Knudsen HK, Ducharme LJ, Roman PM. Clinical supervision, emotional exhaustion, and turnover intention: a study of substance abuse treatment counselors in the Clinical Trials Network of the National Institute on Drug Abuse. Journal of substance abuse treatment. 2008; 35:387-395. [PubMed: 18424048]

30. Olmstead TA, et al. Counselor training in several evidence-based psychosocial addiction treatments in private US substance abuse treatment centers. Drug and alcohol dependence. 2012; 120:149-154. [PubMed: 21831536]

31. McCarty D, et al. Direct care workers in the National Drug Abuse Treatment Clinical Trials Network: Characteristics, opinions, and beliefs. Psychiatric services. 2007; 58:181-190. [PubMed: 17287373] 
32. McGovern MP, et al. A survey of clinical practices and readiness to adopt evidence-based practices: Dissemination research in an addiction treatment system. Journal of substance abuse treatment. 2004; 26:305-312. [PubMed: 15182895]

33. Rieckmann T, et al. Client and counselor attitudes toward the use of medications for treatment of opioid dependence. Journal of Substance Abuse Treatment. 2007; 32:207-215. [PubMed: 17306729]

34. Saxon AJ, McCarty D. Challenges in the adoption of new pharmacotherapeutics for addiction to alcohol and other drugs. Pharmacology \& therapeutics. 2005; 108:119-128. [PubMed: 16055196]

35. Miller, WR.; Rollnick, S. Motivational Interviewing: Preparing People for Change. 2. Guilford Press; New York: 2002.

36. Rogers, EM. Diffusion of Innovations. 4. The Free Press; New York: 1995.

37. Abele M, et al. Teaching Motivational Interviewing Skills to Psychiatry Trainees: Findings of a National Survey. Academic psychiatry : the journal of the American Association of Directors of Psychiatric Residency Training and the Association for Academic Psychiatry. 2014

38. Lindhardt CL, et al. Training in motivational interviewing in obstetrics: a quantitative analytical tool. Acta obstetricia et gynecologica Scandinavica. 2014

39. Imel ZE, et al. Evaluating therapist adherence in motivational interviewing by comparing performance with standardized and real patients. Journal of consulting and clinical psychology. 2014; 82:472-481. [PubMed: 24588405]

40. Martino S, et al. Teaching community program clinicians motivational interviewing using expert and train-the-trainer strategies. Addiction. 2011; 106:428-441. [PubMed: 20925684]

41. Miller WR, et al. A randomized trial of methods to help clinicians learn motivation interviewing. Journal of consulting and clinical psychology. 2004; 72:1050-1062. [PubMed: 15612851]

42. Miller WR, Rollnick S. The effectiveness and ineffectiveness of complex behavioral interventions: impact of treatment fidelity. Contemporary clinical trials. 2014; 37:234-241. [PubMed: 24469237]

43. Petry NM, et al. Serious adverse events in randomized psychosocial treatment studies: safety or arbitrary edicts? Journal of consulting and clinical psychology. 2008; 76:1076-1082. [PubMed: 19045975]

44. Poling J, et al. Six-month trial of bupropion with contingency management for cocaine dependence in a methadone-maintained population. Archives of general psychiatry. 2006; 63:219-228. [PubMed: 16461866]

45. Kosten T, et al. Desipramine and contingency management for cocaine and opiate dependence in buprenorphine maintained patients. Drug and alcohol dependence. 2003; 70:315-325. [PubMed: 12757969]

46. Rounsaville BJ, Carroll KM, Onken LS. A stage model of behavioral therapies research: Getting started and moving on from Stage I. Clinical Psychology: Science and Practice. 2001; 8:133-142.

47. Onken LS, et al. Re-envisioning clinical science: Unifying the discipline to improve the public health. Clinical Psychological Science. 2013; 2:22-34.

48. Carroll KM, Rounsaville BJ. Bridging the gap: a hybrid model to link efficacy and effectiveness research in substance abuse treatment. Psychiatric services. 2003; 54:333-339. [PubMed: 12610240]

49. Fixsen, DL., et al. Implementation Research: A Synthesis of the Literature. University of South Florida, Louis de la Parte Florida Mental Health Institute, the National Implementation Research Network; Tampa: FL: 2005. (FMHI Publication \#231)

50. Bigelow, GE.; Silverman, K. Theoretical and empirical foundations of contingency managment treatments for drug abuse. In: Higgins, ST.; Silverman, K., editors. Motivating behavior change among illicit drug users. American Psychological Association; Washington, DC: 1999. p. 15-31.

51. Stitzer ML, Bigelow GE. Contingency management in a methadone maintenance program: Availability of reinforcers. International Journal of the Addictions. 1978; 13:737-746. [PubMed: 721332]

52. Bigelow, GE.; Stitzer, ML.; Liebson, IA. The role of behavioral contingency management in drug abuse treatment. In: Grabowski, J.; Stitzer, ML.; Henningfield, JE., editors. Behavioral Intervention Techniques in Drug Abuse Treatment. NIDA; Rockville, Maryland: 1984. p. 36-52. 
53. Stitzer ML, et al. Effect of methadone dose contingencies on urinalysis test results of polydrug abusing methadone maintenance patients. Drug and alcohol dependence. 1986; 18:341-348. [PubMed: 3816530]

54. Iguchi MY, et al. Contingency management in methadone maintenance: effects of reinforcing and aversive consequences on illicit polydrug use. Drug and alcohol dependence. 1988; 22:1-7. [PubMed: 2906863]

55. Rounsaville, BJ. Can psychotherapy rescue naltrexone treatment of opioid addiction?. In: Onken, LS.; Blaine, JD., editors. Potentiating the Efficacy of Medications: Integrating Psychosocial Therapies with Pharmacotherapies in the Treatment of Drug Dependence. NIDA; Rockville, MD: 1995. p. 37-52.

56. Greenstein, RA.; Fudala, PJ.; O'Brien, CP. Alternative pharmacotherapies for opiate addiction. In: Lowinson, JH., et al., editors. Comprehensive Textbook of Substance Abuse. Williams \& Wilkins; New York: 1997. p. 415-425.

57. Grabowski J, et al. Effects of contingent payments on compliance with a naltrexone regimen. American Journal of Drug and Alcohol Abuse. 1979; 6:355-365. [PubMed: 539577]

58. Meyer RE, et al. A behavioral paradigm for the evaluation of narcotic antagonists. Archives of general psychiatry. 1976; 33:371-377. [PubMed: 944026]

59. Azrin NH. Improvements in the community-reinforcement approach to alcoholism. Behavior Research \& Therapy. 1976; 14:339-348.

60. Budney, AJ.; Higgins, ST. A Community Reinforcement Plus Vouchers Approach: Treating Cocaine Addiction. NIDA; Rockville, MD: 1998.

61. Higgins ST, et al. A behavioral approach to achieving initial cocaine abstinence. American Journal of Psychiatry. 1991; 148:1218-1224. [PubMed: 1883001]

62. Higgins ST, et al. Achieving cocaine abstinence with a behavioral approach. American Journal of Psychiatry. 1993; 150:763-769. [PubMed: 8480823]

63. Higgins ST, et al. Incentives improve outcome in outpatient behavioral treatment of cocaine dependence. Archives of general psychiatry. 1994; 51:568-576. [PubMed: 8031230]

64. Higgins ST, et al. Contingent reinforcement increases cocaine abstinence during outpatient treatment and one year follow-up. Journal of consulting and clinical psychology. 2000; 68:64-72. [PubMed: 10710841]

65. Silverman K, et al. A reinforcement-based therapeutic workplace for the treatment of drug abuse: Three year abstinence outcomes. Experimental and clinical psychopharmacology. 2002; 10:228240. [PubMed: 12233983]

66. Silverman K, et al. A reinforcement-based therapeutic workplace for the treatment of drug abuse: six-month abstinence outcomes. Experimental and clinical psychopharmacology. 2001; 9:14-23. [PubMed: 11519628]

67. Silverman K, et al. Voucher-based reinforcement of attendance by unemployed methadone patients in a job skills training program. Drug and alcohol dependence. 1996; 41:197-207. [PubMed: 8842632]

68. Schumacher JE, et al. Abstinent-contingent housing and treatment retention among crack-cocainedependent homeless persons. Journal of substance abuse treatment. 2000; 19:81-88. [PubMed: 10867305]

69. Milby JB, et al. Initiating abstinence in cocaine abusing dually diagnosed homeless persons. Drug and alcohol dependence. 2000; 60:55-67. [PubMed: 10821990]

70. Milby JB, et al. Sufficient conditions for effective treatment of substance abusing homeless persons. Drug and alcohol dependence. 1996; 43:39-47. [PubMed: 8957141]

71. Silverman K, et al. Sustained cocaine abstinence in methadone maintenance patients through voucher-based reinforcement therapy. Archives of general psychiatry. 1996; 53:409-415. [PubMed: 8624184]

72. Silverman K, et al. Increasing opiate abstinence through voucher-based reinforcement therapy. Drug and alcohol dependence. 1996; 41:157-165. [PubMed: 8809505]

73. Krishnan-Sarin S, et al. Contingency management for smoking cessation in adolescent smokers. Experimental and clinical psychopharmacology. 2006; 14:306-310. [PubMed: 16893273] 
74. Krishnan-Sarin S, et al. An exploratory randomized controlled trial of a novel high-school-based smoking cessation intervention for adolescent smokers using abstinence-contingent incentives and cognitive behavioral therapy. Drug and alcohol dependence. 2013; 132:346-351. [PubMed: 23523130]

75. Henggeler SW, et al. Multisystemic therapy with violent and chronic juvenile offenders and their families: The role of treatment fidelity. Journal of consulting and clinical psychology. 1997; 65:821-833. [PubMed: 9337501]

76. Henggeler SW, et al. Transporting efficacious treatments to field settings: The link between supervisory practices and therapist fidelity in MST programs. Journal of Clinical Child and Adolescent Psychology. 2002; 31:155-167. [PubMed: 12056100]

77. Henggeler SW, et al. If you build it, they will come: statewide practitioner interest in contingency management for youths. Journal of substance abuse treatment. 2007; 32:121-131. [PubMed: 17306721]

78. Henggeler SW, et al. Statewide adoption and initial implementation of contingency management for substance-abusing adolescents. Journal of consulting and clinical psychology. 2008; 76:556567. [PubMed: 18665685]

79. Henggeler SW, et al. Promoting the implementation of an evidence-based intervention for adolescent marijuana abuse in community settings: testing the use of intensive quality assurance. $\mathbf{J}$ Clin Child Adolesc Psychol. 2008; 37:682-689. [PubMed: 18645758]

80. Henggeler SW, et al. Evaluating training methods for transporting contingency management to therapists. Journal of substance abuse treatment. 2013; 45:466-474. [PubMed: 23910392]

81. Letourneau EJ, et al. Two-year follow-up of a randomized effectiveness trial evaluating MST for juveniles who sexually offend. Journal of family psychology : JFP : journal of the Division of Family Psychology of the American Psychological Association. 2013; 27:978-985.

82. Haynes, RB.; Taylor, DW.; Sackett, DL. Compliance in Health Care. Johns Hopkins University Press; Baltimore, Maryland: 1979.

83. Rigsby MO, et al. Cue dose training with monetary reinforcement: Pilot study of an antiretroviral adherence intervention. Journal of general internal medicine. 2000; 15:841-847. [PubMed: 11119180]

84. Rosen MI, et al. Improved adherence with contingency management. AIDS patient care and STDs. 2007; 21:30-40. [PubMed: 17263651]

85. Sorensen JL, et al. Voucher reinforcement improves medication adherence in HIV-positive methadone patients: a randomized trial. Drug and alcohol dependence. 2007; 88:54-63. [PubMed: 17056206]

86. Preston KL, et al. Improvement in naltrexone treatment compliance with contingency management. Drug and alcohol dependence. 1999; 54:127-135. [PubMed: 10217552]

87. Carroll KM, et al. Contingency management to enhance naltrexone treatment of opioid dependence: A randomized clinical trial of reinforcement magnitude. Experimental and clinical psychopharmacology. 2002; 10:54-63. [PubMed: 11866252]

88. Carroll KM, et al. Targeting behavioral therapies to enhance naltrexone treatment of opioid dependence: efficacy of contingency management and significant other involvement. Archives of general psychiatry. 2001; 58:755-761. [PubMed: 11483141]

89. Petry NM, et al. Financial reinforcers for improving medication adherence: findings from a metaanalysis. The American journal of medicine. 2012; 125:888-896. [PubMed: 22800876]

90. Gritz ER, Toll BA, Warren GW. Tobacco use in the oncology setting: advancing clinical practice and research. Cancer epidemiology, biomarkers \& prevention : a publication of the American Association for Cancer Research, cosponsored by the American Society of Preventive Oncology. 2014; 23:3-9.

91. Heil SH, Higgins ST. The scientific and ethical rationale for using incentives to promote contraceptive use among drug-abusing women. Addiction. 2012; 107:1044-1046. [PubMed: 22563830]

92. Higgins ST, et al. Incentives and health: an introduction. Preventive medicine. 2012; 55(Suppl):S2-6. [PubMed: 22554884] 
93. Heil SH, et al. Effects of voucher-based incentives on abstinence from cigarette smoking and fetal growth among pregnant women. Addiction. 2008; 103:1009-1018. [PubMed: 18482424]

94. Higgins ST, et al. Financial incentives for smoking cessation among pregnant and newly postpartum women. Preventive medicine. 2012; 55(Suppl):S33-40. [PubMed: 22227223]

95. Prendergast M, et al. Contingency management for treatment of substance use disorders: A metaanalysis. Addiction. 2006; 101:1546-1560. [PubMed: 17034434]

96. Lussier JP, et al. A meta-analysis of voucher-based reinforcement therapy for substance use disorders. Addiction. 2006; 101:192-203. [PubMed: 16445548]

97. Griffith JD, et al. Contingency management in outpatient methadone treatment: A meta-analysis. Drug and alcohol dependence. 2000; 58:55-66. [PubMed: 10669055]

98. Petry NM. Contingency management treatments: controversies and challenges. Addiction. 2010; 105:1507-1509. [PubMed: 20707772]

99. Kirby KC, et al. Substance abuse treatment providers' beliefs and objections regarding contingency management: implications for dissemination. Drug and alcohol dependence. 2006; 85:19-27. [PubMed: 16650657]

100. Amodeo M, et al. Barriers to implementing evidence-based practices in addiction treatment programs: comparing staff reports on Motivational Interviewing, Adolescent Community Reinforcement Approach, Assertive Community Treatment, and Cognitive-behavioral Therapy. Evaluation and program planning. 2011; 34:382-389. [PubMed: 21420171]

101. Lundgren L, et al. Barriers to implementation of evidence-based addiction treatment: a national study. Journal of substance abuse treatment. 2012; 42:231-238. [PubMed: 22000323]

102. Carroll KM, Rounsaville BJ. A vision of the next generation of behavioral therapies research in the addictions. Addiction. 2007; 102:850-862. discussion 863-859. [PubMed: 17523974]

103. Petry NM, et al. Give them prizes and they will come: Contingency management treatment of alcohol dependence. Journal of Consulting and Clinical Psychology. 2000; 68:250-257. [PubMed: 10780125]

104. Petry NM, Martin B. Low-cost contingency management for treating cocaine- and opioid abusing methadone patients. Journal of Consulting and Clinical Psychology. 2002; 70:398-405.

[PubMed: 11952198]

105. Petry NM. A comprehensive guide to the application of contingency management procedures in clinical settings. Drug and alcohol dependence. 2000; 58:9-25. [PubMed: 10669051]

106. Petry NM, Simcic F. Recent advances in the dissemination of contingency management techniques: Clinical and research perspectives. Journal of substance abuse treatment. 2002; 23:81-86. [PubMed: 12220605]

107. Petry NM, Bohn MJ. Fishbowls and candy bars: using low-cost incentives to increase treatment retention. Sci Pract Perspect. 2003; 2:55-61. [PubMed: 18552724]

108. Petry NM, Martin B, Finocche C. Contingency management in group treatment: a demonstration project in an HIV drop-in center. Journal of substance abuse treatment. 2001; 21:89-96. [PubMed: 11551737]

109. Petry NM, et al. Contingency management treatments: Reinforcing abstinence versus adherence with goal-related activities. Journal of consulting and clinical psychology. 2006; 74:592-601. [PubMed: 16822115]

110. Petry NM, Ford JD, Barry D. Contingency management is especially efficacious in engendering long durations of abstinence in patients with sexual abuse histories. Psychology of addictive behaviors : journal of the Society of Psychologists in Addictive Behaviors. 2011; 25:293-300. [PubMed: 21443305]

111. Petry NM, Rash CJ, Easton CJ. Contingency management treatment in substance abusers with and without legal problems. J Am Acad Psychiatry Law. 2011; 39:370-378. [PubMed: 21908754]

112. Petry NM, Alessi SM, Rash CJ. A randomized study of contingency management in cocainedependent patients with severe and persistent mental health disorders. Drug and alcohol dependence. 2013; 130:234-237. [PubMed: 23182410]

Ann N Y Acad Sci. Author manuscript; available in PMC 2015 October 01. 
113. Petry NM, Carroll KM. Contingency management is efficacious in opioid-dependent outpatients not maintained on agonist pharmacotherapy. Psychology of addictive behaviors : journal of the Society of Psychologists in Addictive Behaviors. 2013; 27:1036-1043. [PubMed: 23528194]

114. Petry NM, Alessi SM, Rash CJ. Contingency management treatments decrease psychiatric symptoms. Journal of consulting and clinical psychology. 2013; 81:926-931. [PubMed: 23544678]

115. Petry NM, et al. A randomized trial adapting contingency management targets based on initial abstinence status of cocaine-dependent patients. Journal of consulting and clinical psychology. 2012; 80:276-285. [PubMed: 22229758]

116. Petry NM, et al. Using contingency management to optimize outcomes based on initial abstinence status for cocaine dependent patients. Journal of consulting and clinical psychology. in press.

117. Petry NM, Martin B, Simcic F. Prize reinforcement contingency management for cocaine dependence: Integration with group therapy in a methadone clinic. Journal of consulting and clinical psychology. 2005; 73:354-359. [PubMed: 15796645]

118. Petry NM, Weinstock J, Alessi SM. A randomized trial of contingency management delivered in the context of group counseling. Journal of consulting and clinical psychology. 2011; 79:686696. [PubMed: 21806297]

119. Petry NM, et al. Prize reinforcement contingency management for treating cocaine users: How low can we go, and with whom? Addiction. 2004; 99:349-360. [PubMed: 14982548]

120. Petry NM, et al. Vouchers versus prizes: Contingency management of treatment of substance abusers in community settings. Journal of consulting and clinical psychology. 2005; 73:10051014. [PubMed: 16392974]

121. Petry NM, et al. Randomized trial of contingent prizes versus vouchers in cocaine-using methadone patients. Journal of consulting and clinical psychology. 2007; 75:983-991. [PubMed: 18085914]

122. Petry NM, et al. Prize-based contingency management does not increase gambling. Drug and alcohol dependence. 2006; 83:269-273. [PubMed: 16377101]

123. Petry NM, Alessi SM. Prize-based contingency management is efficacious in cocaine-abusing patients with and without recent gambling participation. Journal of substance abuse treatment. 2010; 39:282-288. [PubMed: 20667679]

124. Petry NM, Alessi SM, Ledgerwood DM. Contingency management delivered by community therapists in outpatient settings. Drug and alcohol dependence. 2012; 122:86-92. [PubMed: 21981991]

125. Tai B, et al. The first decade of the National Drug Abuse Treatment Clinical Trials Network: bridging the gap between research and practice to improve drug abuse treatment. Journal of substance abuse treatment. 2010; 38(Suppl 1):S4-13. [PubMed: 20307794]

126. Stitzer ML, Petry NM, Peirce J. Motivational incentives research in the National Drug Abuse Treatment Clinical Trials Network. Journal of substance abuse treatment. 2010; 38(Suppl 1):S61-69. [PubMed: 20307797]

127. Martino S, et al. Partnerships and pathways of dissemination: the National Institute on Drug Abuse-Substance Abuse and Mental Health Services Administration Blending Initiative in the Clinical Trials Network. Journal of substance abuse treatment. 2010; 38(Suppl 1):S31-43. [PubMed: 20307793]

128. Petry NM, et al. Effect of prize-based incentives on outcomes in stimulant abusers in outpatient psychosocial treatment programs: a national drug abuse treatment clinical trials network study. Archives of general psychiatry. 2005; 62:1148-1156. [PubMed: 16203960]

129. Peirce JM, et al. Effects of lower-cost incentives on stimulant abstinence in methadone maintenance treatment: a National Drug Abuse Treatment Clinical Trials Network study. Archives of general psychiatry. 2006; 63:201-208. [PubMed: 16461864]

130. Kirby KC, et al. Is exposure to an effective contingency management intervention associated with more positive provider beliefs? Journal of substance abuse treatment. 2012; 42:356-365. [PubMed: 22116009] 
131. Olmstead TA, Sindelar JL, Petry NM. Cost-effectiveness of prize-based incentives for stimulant abusers in outpatient psychosocial treatment programs. Drug and alcohol dependence. 2007; 87:175-182. [PubMed: 16971054]

132. Olmstead TA, Sindelar JL, Petry NM. Clinic variation in the cost-effectiveness of contingency management. The American Journal on the Addictions. 2007; 16:457-460.

133. Sindelar JL, Olmstead TA, Peirce JM. Cost-effectiveness of prize-based contingency management in methadone maintenance treatment programs. Addiction. 2007; 102:1463-1471. [PubMed: 17645428]

134. Walker R, et al. Disseminating contingency management to increase attendance in two community substance abuse treatment centers: lessons learned. Journal of substance abuse treatment. 2010; 39:202-209. [PubMed: 20598838]

135. Pilling S, Strang J, Gerada C. Psychosocial interventions and opioid detoxification for drug misuse: summary of NICE guidance. Bmj. 2007; 335:203-205. [PubMed: 17656545]

136. Petry NM, et al. Nationwide dissemination of contingency management: The veterans administration initiative. The American Journal on Addictionsn/a-n/a. 2013

137. Rash CJ, et al. Identifying provider beliefs related to contingency management adoption using the contingency management beliefs questionnaire. Drug and alcohol dependence. 2012; 121:205212. [PubMed: 21925807]

138. Tolin DF. Is cognitive-behavioral therapy more effective than other therapies? A meta-analytic review. Clinical psychology review. 2010; 30:710-720. [PubMed: 20547435]

139. Marlatt, GA.; Gordon, JR. Relapse Prevention: Maintenance Strategies in the Treatment of Addictive Behaviors. Guilford; New York: 1985.

140. Marlatt, GA.; Gordon, GR. Determinants of relapse: Implications for the maintenance of behavior change. In: Davidson, PO.; Davidson, SM., editors. Behavioral Medicine: Changing Health Lifestyles. Brunner/Mazel; New York: 1980. p. 410-452.

141. Meichenbaum, DH. Cognitive-behavioral therapy in historical perspective. In: Bongar, BM.; Beutler, LE., editors. Comprehensive Textbook of Psychotherapy: Theory and Practice. Oxford University Press; New York: 1995. p. 140-158.

142. Chaney EF, O’Leary MR, Marlatt GA. Skill training with problem drinkers. Journal of consulting and clinical psychology. 1978; 46:1092-1104. [PubMed: 701544]

143. Magill M, Ray LA. Cognitive-behavioral treatment with adult alcohol and illicit drug users: a meta-analysis of randomized controlled trials. Journal of studies on alcohol and drugs. 2009; 70:516-527. [PubMed: 19515291]

144. Anton RF, et al. Naltrexone and cognitive-behavioral therapy for the treatment of outpatient alcoholics: Results of a placebo-controlled trial. American Journal of Psychiatry. 1999; 156:1758-1764. [PubMed: 10553740]

145. O'Malley SS, et al. Naltrexone and coping skills therapy for alcohol dependence: A controlled study. Archives of general psychiatry. 1992; 49:881-887. [PubMed: 1444726]

146. Morgenstern J, et al. Manual-guided cognitive behavioral therapy training: A promising method for disseminating empirically supported substance abuse treatments to the practice community. Psychology of Addictive Behaviors. 2001; 15:83-88. [PubMed: 11419234]

147. Carroll, KM.; Ball, SA.; Martino, S. Cognitive, behavioral, and motivational therapies. In: Galanter, M.; Kleber, HD., editors. The American Psychiatric Publishing Textbook of Substance Abuse Treatment. 3. American Psychiatric Publishing; Washington, DC: 2004. p. 365-376.

148. Santa Ana EJ, et al. What is usual about "treatment-as-usual"? Data from two multisite effectiveness trials. Journal of substance abuse treatment. 2008; 35:369-379. [PubMed: 18337053]

149. Carroll KM. Treatment integrity and dissemination: Rethinking fidelity via the Stage Model. Clinical Psychology: Science and Practice. 2013; 20:99-106.

150. Carroll KM, Rounsaville BJ, Keller DS. Relapse prevention strategies in the treatment of cocaine abuse. American Journal of Drug and Alcohol Abuse. 1991; 17:249-265. [PubMed: 1928020]

151. Carroll KM, Rounsaville BJ, Gawin FH. A comparative trial of psychotherapies for ambulatory cocaine abusers: Relapse prevention and interpersonal psychotherapy. American Journal of Drug and Alcohol Abuse. 1991; 17:229-247. [PubMed: 1928019] 
152. Woody GE, et al. Psychotherapy in community methadone programs: A validation study. American Journal of Psychiatry. 1995; 152:1302-1308. [PubMed: 7653685]

153. Woody GE, et al. Psychotherapy for opiate addicts. NIDA research monograph. 1983; 43:59-70. [PubMed: 6410280]

154. Project MATCH Research Group. Matching Alcohol Treatments to Client Heterogeneity: Project MATCH posttreatment drinking outcomes. Journal of studies on alcohol. 1997; 58:7-29. [PubMed: 8979210]

155. Carroll KM, et al. Treatment of cocaine and alcohol dependence with psychotherapy and disulfiram. Addiction. 1998; 93:713-727. [PubMed: 9692270]

156. Carroll KM, et al. Psychotherapy and pharmacotherapy for ambulatory cocaine abusers. Archives of general psychiatry. 1994; 51:177-197. [PubMed: 8122955]

157. Carroll KM, et al. The use of contingency management and motivational/skills-building therapy to treat young adults with marijuana dependence. Journal of consulting and clinical psychology. 2006; 74:955-966. [PubMed: 17032099]

158. Carroll KM, et al. Efficacy of disulfiram and cognitive behavior therapy in cocaine-dependent outpatients: a randomized placebo-controlled trial. Archives of general psychiatry. 2004; 61:264272. [PubMed: 14993114]

159. Carroll KM, et al. Treatment of cocaine and alcohol dependence with psychotherapy and disulfiram. Addiction. 1998; 93:713-728. [PubMed: 9692270]

160. Carroll KM, et al. One year follow-up of disulfiram and psychotherapy for cocaine-alcohol abusers: Sustained effects of treatment. Addiction. 2000; 95:1335-1349. [PubMed: 11048353]

161. Carroll KM, et al. One year follow-up of psychotherapy and pharmacotherapy for cocaine dependence: Delayed emergence of psychotherapy effects. Archives of General Psychiatry. 1994; 51:989-997. [PubMed: 7979888]

162. Carroll KM, Nich C, Ball SA. Practice makes progress: Homework assignments and outcome in the treatment of cocaine dependence. Journal of Consulting and Clinical Psychology. 2005; 73:749-755. [PubMed: 16173864]

163. Epstein DE, et al. Cognitive behavioral therapy plus contingency management for cocaine use: Findings during treatment and across 12-month follow-up. Psychology of Addictive Behaviors. 2003; 17:73-82. [PubMed: 12665084]

164. Anton RF, et al. Naltrexone combined with either cognitive behavioral or motivational enhancement therapy for alcohol dependence. Journal of clinical psychopharmacology. 2005; 25:349-357. [PubMed: 16012278]

165. O'Malley SS, et al. Naltrexone and cognitive behavioral coping skills therapy for the treatment of alcohol drinking and eating disorder features in alcohol-dependent women: a randomized controlled trial. Alcoholism, clinical and experimental research. 2007; 31:625-634.

166. Rawson RA, et al. A comparison of contingency management and cognitive-behavioral approaches during methadone maintenance for cocaine dependence. Archives of general psychiatry. 2002; 59:817-824. [PubMed: 12215081]

167. McKay JR, et al. Group counseling versus individualized relapse prevention aftercare following intensive outpatient treatment for cocaine dependence: initial results. Journal of consulting and clinical psychology. 1997; 65:778-788. [PubMed: 9337497]

168. Monti PM, et al. Brief coping skills treatment for cocaine abuse: Substance abuse outcomes at three months. Addiction. 1997; 92:1717-1728. [PubMed: 9581004]

169. Ito JR, Donovan DM, Hall JJ. Relapse prevention in alcohol aftercare: effects on drinking outcome, change process and aftercare attendance. British journal of addiction. 1988; 83:171181. [PubMed: 2830931]

170. Carroll KM, et al. Internal validity of Project MATCH treatments: Discriminability and integrity. Journal of Consulting and Clinical Psychology. 1998; 66:290-303. [PubMed: 9583332]

171. Carroll KM, et al. A general system for evaluating therapist adherence and competence in psychotherapy research in the addictions. Drug and Alcohol Dependence. 2000; 57:225-238. [PubMed: 10661673]

172. Carroll KM, et al. Internal validity of Project MATCH treatments: discriminability and integrity. Journal of consulting and clinical psychology. 1998; 66:290-303. [PubMed: 9583332] 
173. Carroll KM, Nich C, Rounsaville BJ. Use of observer and therapist ratings to monitor delivery of coping skills treatment for cocaine abusers: Utility of therapist session checklists. Psychotherapy Research. 1998; 8:307-320.

174. Martino S, et al. Correspondence of motivational enhancement treatment integrity ratings among therapists, supervisors, and observers. Psychotherapy Research. 2009; 19:181-193. [PubMed: 19396649]

175. Hogue A, et al. Validity of therapist self-report ratings of fidelity to evidence-based practices for adolescent behavior problems: Correspondence between therapists and observers. Administration and policy in mental health. in press.

176. Ball SA, et al. Characteristics of community clinicians trained to provide manual-guided therapy for substance abusers. Journal of substance abuse treatment. 2002; 23:309-318. [PubMed: 12495792]

177. Santa Ana EJ, et al. Evaluating motivational enhancement therapy adherence and competence among Spanish-speaking therapists. Drug and alcohol dependence. 2009; 103:44-51. [PubMed: 19394164]

178. Sholomskas D, et al. We don't train in vain: A dissemination trial of three strategies for training clinicians in cognitive behavioral therapy. Journal of Consulting and Clinical Psychology. 2005; 73:106-115. [PubMed: 15709837]

179. Rawson RA, et al. Dissemination and implementation of cognitive behavioral therapy for stimulant dependence: a randomized trial comparison of 3 approaches. Substance abuse : official publication of the Association for Medical Education and Research in Substance Abuse. 2013; 34:108-117. [PubMed: 23577903]

180. Martino S, et al. A criterion-based stepwise approach for training counselors in motivational interviewing. Journal of substance abuse treatment. 2011; 40:357-365. [PubMed: 21316183]

181. Webb CA, Derubeis RJ, Barber JP. Therapist adherence/competence and treatment outcome: A meta-analytic review. Journal of consulting and clinical psychology. 2010; 78:200-211. [PubMed: 20350031]

182. Beidnas RS, Kendall PC. Training therapists in evidence-based practice: A critical review of studies from a systems-contextual perspective. Clinical Psychology: Science and Practice. 2010; 17:1-30. [PubMed: 20877441]

183. Schoenwald SK, Sheidow AJ, Chapman JE. Clinical supervision in treatment transport: Effects on adherence and outcomes. Journal of Consulting and Clinical Psychology. 2009; 77:410-421. [PubMed: 19485583]

184. Carroll KM, Rounsaville BJ. Computer-assisted therapy in psychiatry: Be brave-it's a new world. Current psychiatry reports. 2010; 12:426-432. [PubMed: 20683681]

185. Carroll KM, et al. Computer-assisted cognitive-behavioral therapy for addiction. A randomized clinical trial of 'CBT4CBT'. American Journal of Psychiatry. 2008; 165:881-888. [PubMed: 18450927]

186. Carroll KM, et al. Enduring effects of a computer-assisted training program for cognitivebehavioral therapy: A six-month follow-up of CBT4CBT. Drug and alcohol dependence. 2009; 100:178-181. [PubMed: 19041197]

187. Carroll KM, et al. Enduring effects of a computer-assisted training program for cognitive behavioral therapy: a 6-month follow-up of CBT4CBT. Drug Alcohol Depend. 2009; 100:178181. [PubMed: 19041197]

188. Carroll KM, et al. Computer-Assisted Delivery of Cognitive-Behavioral Therapy: Efficacy and Durability of CBT4CBT Among Cocaine-Dependent Individuals Maintained on Methadone. The American journal of psychiatry. 2014; 171:436-444. [PubMed: 24577287]

189. Hedman E, Ljotsson B, Lindefors N. Cognitive behavior therapy via the Internet: a systematic review of applications, clinical efficacy and cost-effectiveness. Expert review of pharmacoeconomics \& outcomes research. 2012; 12:745-764. [PubMed: 23252357]

190. McCrone P, et al. Cost-effectiveness of computerized cognitive-behavioral therapy for anxiety and depression in primary care: Randomized controlled trial. British Journal of Psychiatry. 2004; 185:55-62. [PubMed: 15231556] 
191. Olmstead TA, Ostrow CD, Carroll KM. Cost-effectiveness of computer-assisted training in cognitive-behavioral therapy as an adjunct to standard care for addiction. Drug and alcohol dependence. 2010; 110:200-207. [PubMed: 20392575]

192. Bickel WK, et al. Computerized behavior therapy for opioid-dependent outpatients: a randomized controlled trial. Experimental and clinical psychopharmacology. 2008; 16:132-143. [PubMed: 18489017]

193. Kypri K, et al. Web-based alcohol screening and brief intervention for university students: a randomized trial. JAMA : the journal of the American Medical Association. 2014; 311:12181224.

194. Marsch LA, Bickel WK, Grabinski MJ. Application of interactive, computer technology to adolescent substance abuse prevention and treatment. Adolesc Med State Art Rev. 2007; 18:342356. xii. [PubMed: 18605650]

195. Campbell AN, et al. Internet-Delivered Treatment for Substance Abuse: A Multisite Randomized Controlled Trial. The American journal of psychiatry. 2014

196. Hester RK, et al. A web application for moderation training: initial results of a randomized clinical trial. Journal of substance abuse treatment. 2009; 37:266-276. [PubMed: 19339137]

197. Carey KB, et al. Computer-delivered interventions to reduce college student drinking: a metaanalysis. Addiction. 2009; 104:1807-1819. [PubMed: 19744139]

198. Rooke S, et al. Computer-delivered interventions for alcohol and tobacco use: a meta-analysis. Addiction. 2010; 105:1381-1390. [PubMed: 20528806]

199. Tait RJ, Spijkerman R, Riper H. Internet and computer based interventions for cannabis use: A meta-analysis. Drug and alcohol dependence. 2013

200. Kiluk BD, et al. A methodological analysis of randomized clinical trials of computer-assisted therapies for psychiatric disorders: toward improved standards for an emerging field. The American journal of psychiatry. 2011; 168:790-799. [PubMed: 21536689]

201. Bickel WK, Christensen DR, Marsch LA. A review of computer-based interventions used in the assessment, treatment, and research of drug addiction. Substance use \& misuse. 2011; 46:4-9. [PubMed: 21190401]

202. Olmstead TA, Petry NM. The cost-effectiveness of prize-based and voucher-based contingency management in a population of cocaine- or opioid-dependent outpatients. Drug and alcohol dependence. 2009; 102:108-115. [PubMed: 19324501]

203. Madras BK, et al. Screening, brief interventions, referral to treatment (SBIRT) for illicit drug and alcohol use at multiple healthcare sites: comparison at intake and 6 months later. Drug and alcohol dependence. 2009; 99:280-295. [PubMed: 18929451]

204. Miller WR. Bringing addiction treatment out of the closet. Addiction. 2007; 102:867.

205. Roche AM, Todd CL, O'Connor J. Clinical supervision in the alcohol and other drugs field: an imperative or an option? Drug and alcohol review. 2007; 26:241-249. [PubMed: 17454013]

206. Karlin BE, Cross G. From the laboratory to the therapy room: National dissemination and implementation of evidence-based psychotherapies in the U.S. Department of Veterans Affairs Health Care System. The American psychologist. 2014; 69:19-33. [PubMed: 24001035]

207. Glasner-Edwards S, Rawson R. Evidence-based practices in addiction treatment: review and recommendations for public policy. Health policy. 2010; 97:93-104. [PubMed: 20557970]

208. Eby LT, Burk H, Maher CP. How serious of a problem is staff turnover in substance abuse treatment? A longitudinal study of actual turnover. Journal of substance abuse treatment. 2010; 39:264-271. [PubMed: 20675097]

209. Institute of Medicine. Crossing the Quality Chasm: A New Mental Health System for the 21st Century. National Academy Press; Washington DC: 2001.

210. McLellan AT, Chalk M, Bartlett J. Outcomes, performance, and quality: What's the difference? Journal of substance abuse treatment. 2007; 32:331-340. [PubMed: 17481456]

211. Carroll KM, et al. Toward empirical identification of a clinically meaningful indicator of treatment outcome: Features of candidate indicators and evaluation of sensitivity to treatment effects and relationship to one year follow up cocaine use outcomes. Drug and alcohol dependence. 2014; 137:3-19. [PubMed: 24556275] 
212. Fletcher, A. Inside Rehab: The Surprising Truth About Addiction Treatment. Viking Press; New York: 2013.

213. Donovan DM, et al. Primary outcome indices in illicit drug dependence treatment research: systematic approach to selection and measurement of drug use end-points in clinical trials. Addiction. 2012; 107:694-708. [PubMed: 21781202]

214. Humphreys K, McLellan AT. A policy-oriented review of strategies for improving the outcomes of services for substance use disorder patients. Addiction. 2011; 106:2058-2066. [PubMed: 21631620]

215. Carroll KM, et al. Toward empirical identification of a clinically meaningful indicator of treatment outcome: Features of candidate indicators and evaluation of sensitivity to treatment effects and relationship to one year follow up cocaine use outcomes. Drug and alcohol dependence. 2014; 137C:3-19. [PubMed: 24556275]

216. Chassin MR, et al. Accountability measures--using measurement to promote quality improvement. The New England journal of medicine. 2010; 363:683-688. [PubMed: 20573915]

217. McLellan AT, et al. Improving public addiction treatment through performance contracting: the Delaware experiment. Health policy. 2008; 87:296-308. [PubMed: 18325621]

218. Garnick DW, et al. Performance measures for substance use disorders--what research is needed? Addiction science \& clinical practice. 2012; 7:18. [PubMed: 23186374] 